\title{
Efficacy of Medications Approved for the Treatment of Alcohol Dependence and Alcohol Withdrawal Syndrome in Female Patients: A Descriptive Review
}

\author{
Roberta Agabio ${ }^{a}$ Pier Paolo Panib Antonio Pretic Gian Luigi Gessa ${ }^{a}$ d \\ Flavia Franconi ${ }^{\mathrm{e}}$ \\ a Department of Biomedical Sciences, Section of Neuroscience and Clinical Pharmacology, University of Cagliari, \\ bSocial-Health Services, Cagliari Health Public Trust (ASL Cagliari), ' Unit of Psychosomatics and Clinical Psychiatry, \\ University Hospital, University of Cagliari, ${ }^{\mathrm{d}}$ Neuroscience Institute, National Research Council of Italy, Section of Cagliari,

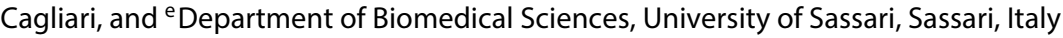

\section{Key Words}

Alcohol dependence - Alcohol withdrawal syndrome .

Women · Pharmacotherapy · Gender differences

\section{Abstract}

The aim of this study was to evaluate whether the number of women recruited for studies to establish the efficacy of medications approved for treatment of alcohol dependence (AD) and of alcohol withdrawal syndrome (AWS) is sufficient to reveal possible gender differences in the response to these medications and in suggesting the use of different doses in female patients. Our results show that the rates of women recruited for studies evaluating the efficacy of disulfiram (1\%), benzodiazepines (3\%), and anticonvulsants (13\%) were too low to establish possible gender differences. The rates of women recruited for studies evaluating the efficacy of acamprosate (22\%), naltrexone (23\%), and naImefene (30\%) were higher and allowed evaluation of data obtained for female patients. Women receive medications for treatment of AD and/or AWS for which efficacy has been demonstrated in studies in which men were more largely represented.

\section{Introduction}

Pharmacotherapy is emerging as a valuable tool for the treatment of alcohol dependence (AD), but only a few medications are available to date. Currently, medications approved in the United Kingdom and/or in the United States for AD treatment to help patients achieve abstinence, or at least to reduce alcohol consumption, comprise disulfiram, naltrexone, acamprosate, nalmefene and gamma-hydroxybutyrate (GHB) [1-3].

Briefly, disulfiram is the oldest medication for the treatment of AD, approved by the FDA since 1948 [3]. Its mechanism of action involves inhibition of aldehyde dehydrogenase $(\mathrm{ALDH})$, the enzyme responsible for converting acetaldehyde to acetate during alcohol metabolism, which leads to the accumulation of acetaldehyde after alcohol intake [4]. Accumulation of acetaldehyde causes a consequent aversive reaction that deters further alcohol use [5]. Accordingly, disulfiram is indicated for the prevention of relapse in abstinent patients.

\section{G.L.G. and F.F. contributed equally to this work.}


Naltrexone is a competitive antagonist of $\mu$-opioid receptors, approved by the FDA in 1994 for the treatment of $\mathrm{AD}[2,3]$. Its mechanism of action is not fully understood [2]. As the rewarding effects of alcohol are partly mediated through the opioid receptors, blocking of these receptors could explain the reduction in reward effects induced by alcohol consumption and subsequently the reductions in intake and cravings for alcohol [6]. Concerns about low adherence for oral formulations led to the development of slow-release formulations of naltrexone [6].

Nalmefene is a $\mu$-opioid antagonist, like naltrexone, but, compared to naltrexone, nalmefene has a longer plasma half-life, higher bioavailability, and lower liver toxicity [7]. This medication has been recently approved by the European Committee for Medicinal Products for Human Use for the treatment of $\mathrm{AD}$ [8].

In the United States, acamprosate is currently the most widely prescribed medication to prevent AD relapse $[9$, 10]. The mechanism of action of acamprosate is not completely known. It shares similarities with several amino acids, such as glutamate, gamma-aminobutyric acid, aspartate, glycine, and taurine [11]. Converging evidence indicates that acamprosate normalises a hyper-glutamatergic state caused by extensive alcohol exposure and repeated phases of alcohol withdrawal, restoring the balance between inhibitory and excitatory neurotransmitters, and attenuating alcohol craving [12].

GHB is an endogenous neurochemical currently marketed in some European countries for the treatment of $\mathrm{AD}$ [13]. The mechanism of action of GHB in the treatment of AD is substitutive [1]. While substitution therapy carriers a lower risk than the use of the substance of abuse, the substitute also has a potential for abuse, and cases of GHB intoxication have been reported [14, 15]. For this reason, in the United States, GHB has not been approved for the treatment of AD [13].

Finally, medications approved in the Europe and/or the United States for the treatment of alcohol withdrawal syndrome (AWS) comprise benzodiazepines (e.g. diazepam, chlordiazepoxide, and lorazepam), anticonvulsants (e.g. carbamazepine, valproic acid, and phenytoin), and GHB [16-18].

Unfortunately, AD medications are not effective in all patients, and the magnitude of the response to these medications is generally modest [3]. To improve the efficacy of $\mathrm{AD}$ medications, there is growing interest in investigating possible factors that mediate the response to pharmacotherapy, such as different patient characteristics and genetic factors $[19,20]$. It is notable that women and men vary largely in terms of biological and psychosocial-cul- tural factors involved in the response to medical treatments, and sex differences in response to medications have been described for several treatment methods [2125]. For instance, it has been observed that women eliminate the hypnotic medication zolpidem more slowly than men do, and lower doses of this medication have been recommended for women compared to men [26, 27]. Similarly, women could differ from men in the response to medications approved for treatment of $\mathrm{AD}$ and/or AWS.

Women differ from men with regard to several AD aspects [28-34]. This mental disorder is twice as prevalent in men as in women [35], although women suffer serious negative consequences of alcohol consumption much early in life and to a greater degree than men. In addition, women also experience specific alcohol-related problems, such as the risk of foetal alcohol syndrome if alcohol is consumed during pregnancy $[36,37]$. The higher vulnerability to the development of alcohol-related consequences in women is, at least in part, due to sex differences in alcohol pharmacokinetics. The risk of medical consequences is related to blood alcohol concentration, and after drinking equivalent amounts of alcohol, women achieve higher blood alcohol concentration than men of similar body weight [38-40]. This occurs because women have a smaller volume of distribution (due to a higher proportion of body fat and lower body water than men) and a lower first-pass metabolism of alcohol than men (because of lower levels of the gastric enzyme that metabolises alcohol: alcohol dehydrogenase) [38]. For these reasons, women are advised to consume lower amounts of alcohol than men do.

Gender difference has also been described as an important factor in determining alcohol consumption, as well as the response to alcohol at comparable blood alcohol concentration. For instance, in humans and non-human adult primates, males consume higher amounts of alcohol than females $[33,41]$ do, while in rodents, females consume higher amounts of alcohol than males [42, 43]. Moreover, aggressive behaviour after alcohol consumption is less evident in women than in men [44], and female rats are more sensitive than males to alcohol-induced hypothermia [45]. Both animal and clinical studies have found that females tend to develop less severe AWS than males $[31,46]$. Complex interactions between intrinsic sex differences in brain organization and the activational effects of circulating gonadal steroids, neuroactive steroids (steroids synthesised in the brain, adrenals, and gonads that affect neuronal excitability), and stress hormones have been proposed to explain these findings [47, 48]. For instance, as allopregnanolone, a metabolite of 
progesterone, has shown an anticonvulsant effect in some preclinical models, the current hypothesis is that females and males might have different sensitivity to AWS owing to the effects of neurosteroids $[47,49]$. Some of the sex differences observed in alcohol consumption and/or in responses to alcohol have been attributed to differences in levels of oestrogens and androgens between women and men. Indeed, it has been observed that oestrogen and androgen levels modulate the mesocorticolimbic 'reward' dopaminergic system [50], and that women release less amounts of dopamine in the ventral striatum compared to men after acute alcohol consumption [51]. Human and preclinical studies have also shown that the pattern of alcohol consumption varies throughout the different phases of the menstrual cycle, and these differences have been attributed, at least in part, to different levels of oestrogens and progesterone [50].

In view of all these sex differences, it can be hypothesised that women and men might also differ in their response to medications approved for treatment of $\mathrm{AD}$ and/or AWS, and might require different doses of these medications. To test this hypothesis, we performed a descriptive review of studies on the efficacy of these medications to evaluate: (a) whether a sufficient number of women were recruited to evaluate possible sex differences in the response; (b) if the number of women was sufficient, whether sex differences in the response were observed; and (c) the doses administered in these studies. To this end, recent meta-analyses evaluating the efficacy of $\mathrm{AD}$ and/or AWS medications were selected. From these meta-analyses, data on female patients and medication doses administered were collected. When this information was not available in the selected meta-analyses, the primary clinical trials were examined.

\section{Methods}

Search Methods for Identification of Reviews

A systematic search was conducted on PubMed/Medline and the Cochrane database of Systematic Reviews to identify metaanalyses on the efficacy of medications approved for AD and AWS treatment. A first systematic search was conducted using the keywords 'pharmacological treatment (mesh) AND alcohol dependence (mesh)', and a second systematic search using the keywords 'pharmacological treatment (mesh) AND alcohol withdrawal syndrome'. In both searches, the filters meta-analysis, Humans, and English language were activated. The search was performed in August 2014. When no meta-analysis was found for a medication, a manual search throughout the reading of the other selected metaanalyses was conducted. When more than one eligible meta-analysis was available for the same medication, the more recent one was selected.

Medications for AD Women

\section{Criteria for Considering Reviews for Inclusion}

Only meta-analyses on the efficacy of medications already approved for $\mathrm{AD}$ and/or AWS treatment were included. Other inclusion criteria were (1) use of rigorous methods to minimise bias, (2) diagnosis of $\mathrm{AD}$ and/or AWS according to appropriate standard criteria (e.g. the criteria of Diagnostic and Statistical Manual of Mental Disorders), and (3) comparison between the results obtained by patients treated with the pharmacological intervention and those obtained by patients treated with placebo. Recent primary clinical trials not yet part of the selected meta-analyses were not included. In the first search, only meta-analyses on one of the following medications were included: (1) naltrexone, (2) acamprosate, (3) nalmefene, (4) disulfiram, and (5) GHB. In the second search, only meta-analyses on one of the following medications approved for AWS treatment were included: (1) benzodiazepines, (2) anticonvulsants, and (3) GHB.

Assessment of the Methodological Quality of Included Reviews

The quality of the included reviews was not evaluated, as it was assured by selecting meta-analyses.

\section{Data Extraction and Management}

From each selected meta-analysis, the following information was collected: (1) number of randomised controlled trials (RCTs) evaluated; (2) number of patients recruited by these RCTs; (3) number of RCTs in which only male patients were recruited; (4) number of RCTs in which the sex of patients was not indicated; (5) number of RCTs in which female and male patients were recruited; (6) number of RCTs in which only female patients were recruited; (7) medication doses administered (when this information was not specified by the meta-analysis, it was obtained from the original article on the RCT); and (8) levels of medication efficacy assigned by the meta-analysis, regardless of patient sex. From this information, the following data were calculated: (1) the rate of female patients among patients for whom sex was known; (2) the highest and lowest doses used in any RCTs.

\section{Sufficient Number of Female Patients Recruited for RCTs}

Considering that the lifetime prevalence of $\mathrm{AD}$ is twice as high in men as in women [35], female patients should constitute approximately one-third of the sample of patients recruited in studies evaluating the efficacy of medications for this disorder (33\% of patients).

\section{Assessment of Efficacy}

For each medication (or class of medications), the efficacy, regardless of the sex of the patient, evaluated by the selected metaanalysis was expressed in levels (table 1) [52-54]. When a metaanalysis showed superiority of a medication to placebo, level A1 was assigned; when a meta-analysis did not show superiority of a medication to placebo, level $\mathrm{C}$ was assigned. The efficacy of each medication in female patients was assigned according to the criteria provided in table 1 , considering the source of the evidence and possible negative results.

\section{Results}

The first search for meta-analyses of medications approved for $\mathrm{AD}$ treatment identified 79 articles. Among these, 75 were excluded (see online suppl. references; 
Table 1. Levels of efficacy

\begin{tabular}{lll}
\hline Level & Source of the evidence & If negative RCTs do exist \\
\hline A1 & $\begin{array}{l}\text { One meta-analysis shows superiority to placebo } \\
\text { (with a narrow confidence interval in at least 3 RCTs, } \\
\text { at least one of which was large) }\end{array}$ & They have already been evaluated by the meta-analysis \\
\hline A2 & $\begin{array}{l}\text { At least 2 positive RCTs show superiority to placebo } \\
\text { (with a narrow confidence interval in at least 1 large } \\
\text { RCT) }\end{array}$ & $\begin{array}{l}\text { They are outweighed by: } \\
\text { (1) a meta-analysis on all available studies showing } \\
\text { non-inferiority to an established comparator treatment, or } \\
\text { (2) at least 2 more positive studies showing superiority to placebo }\end{array}$ \\
\hline B & One or more RCTs shows superiority to placebo & $\begin{array}{l}\text { They are outweighed by: } \\
\text { (1) a meta-analysis of all available studies showing } \\
\text { non-inferiority to an established comparator treatment, or } \\
\text { (2) at least 1 more positive study showing superiority to placebo }\end{array}$ \\
\hline C & Inconsistent evidence from any number of RCTs & \begin{tabular}{l} 
They are not outweighed by positive RCTs \\
\hline
\end{tabular}
\end{tabular}

This table summarises how the level of efficacy was established, considering the source of the evidence and possible negative results. RCTs $=$ Randomised, controlled trials based on a double-blind, parallel-group design. Large $=$ Number of patients recruited $\geq 100$ subjects.

for all online suppl. material, see www.karger.com/doi/ 10.1159/000433579) and 4 were selected [55-58] (table 2). Another article was added after a manual search [59]. One meta-analysis specifically investigated the efficacy of acamprosate in AD women [57]. Reasons for exclusion of meta-analyses are listed in online supplementary table S1. Information collected from the selected meta-analyses is summarised in table 2 .

Briefly, the meta-analysis selected for disulfiram evaluated the results obtained by 11 RCTs in which 1,521 patients were recruited and did not find a significant effect of this medication on abstinence, regardless of patient sex [59]. Accordingly, the level C of efficacy was assigned to this medication (table 2). The rates of women recruited in these 11 RCTs are shown by table 3. Globally, (a) 7 RCTs recruited only male patients ( $\mathrm{n}=1,133$ men), (b) 1 study did not indicate the gender of subjects $(\mathrm{n}=39$ patients), whereas (c) 3 RCTs recruited both male and female patients ( 92 women in a total sample of 349 patients $(26.4 \%)$ ). Among the 1,482 patients for whom the sex was known, 92 were women $(6.2 \%)$. Only 3 RCTs compared disulfiram to placebo, and the rate of women recruited in these RCTs was too low ( 9 women in a sample of 759 patients $(1.2 \%)$ ) to allow a gender analysis (tables 2 and 3; fig. 1). The dose of disulfiram ranged from $100 \mathrm{mg}$ per day to $800 \mathrm{mg}$ twice a week [59]. Only one study included in the meta-analysis adjusted the daily dose of disulfiram according to body weight [60]. In this study, the dose of disulfiram was 100 or $200 \mathrm{mg}$ once a day, or $400 \mathrm{mg}$ twice a week, but it was not specified whether women received lower doses of disulfiram than men did [60].

The meta-analysis selected for acamprosate evaluated the results obtained by 24 RCTs and found that this medication significantly reduced the risk of any drinking after detoxification (14\% lower risk), and increased the cumulative duration of abstinence ( 3 additional days a month) [56]. According to these results, the level A1 of efficacy for $\mathrm{AD}$ treatment was assigned to acamprosate, regardless of sex (table 2). The rates of women recruited in these 24 RCTs are shown by table 4 . Globally, (a) 2 RCTs recruited only male patients ( $\mathrm{n}=85 \mathrm{men}$ ), whereas (b) the other 22 RCTs recruited both female and male patients $(1,326$ women in a sample of 6,062 patients $(21.9 \%)$ ). All the RCTs compared acamprosate to placebo. Among the total sample of patients ( $n=6,147$ patients), 1,326 were women (21.9\%). The rate of women recruited for RCTs evaluating the efficacy of acamprosate was close to the real frequency of female patients with $\mathrm{AD}$ and allowed a gender analysis (tables 2 and 4; fig. 1). Specifically, the second meta-analysis selected found no sex differences in all the outcomes evaluated [57]. According to these results, the level A1 of efficacy for AD treatment was assigned to acamprosate for $\mathrm{AD}$ female patients (table 2). The daily dose of acamprosate ranged from 1,332 to $3,000 \mathrm{mg}$; in most studies, the dose was adjusted according to body weight $(1,332 \mathrm{mg}$ for body weight $<60 \mathrm{~kg} ; 1,998 \mathrm{mg}$ for $\geq 60 \mathrm{~kg}$ ) [56]. It was not specified whether women received lower doses of acamprosate than men did. 


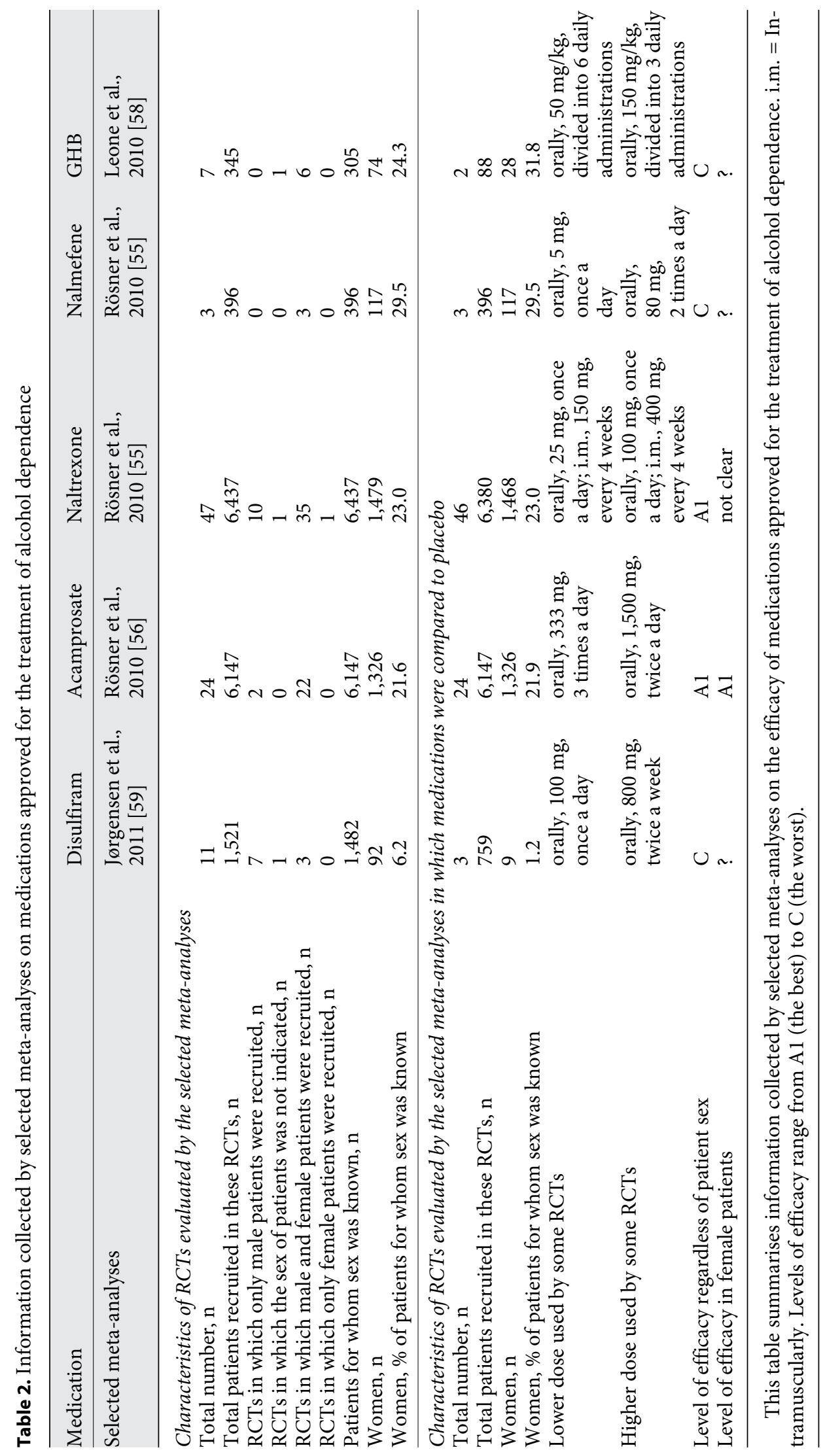


Fig. 1. Rates of male and female patients recruited in randomised, placebo-controlled trials conducted to evaluate the efficacy of AD medications.

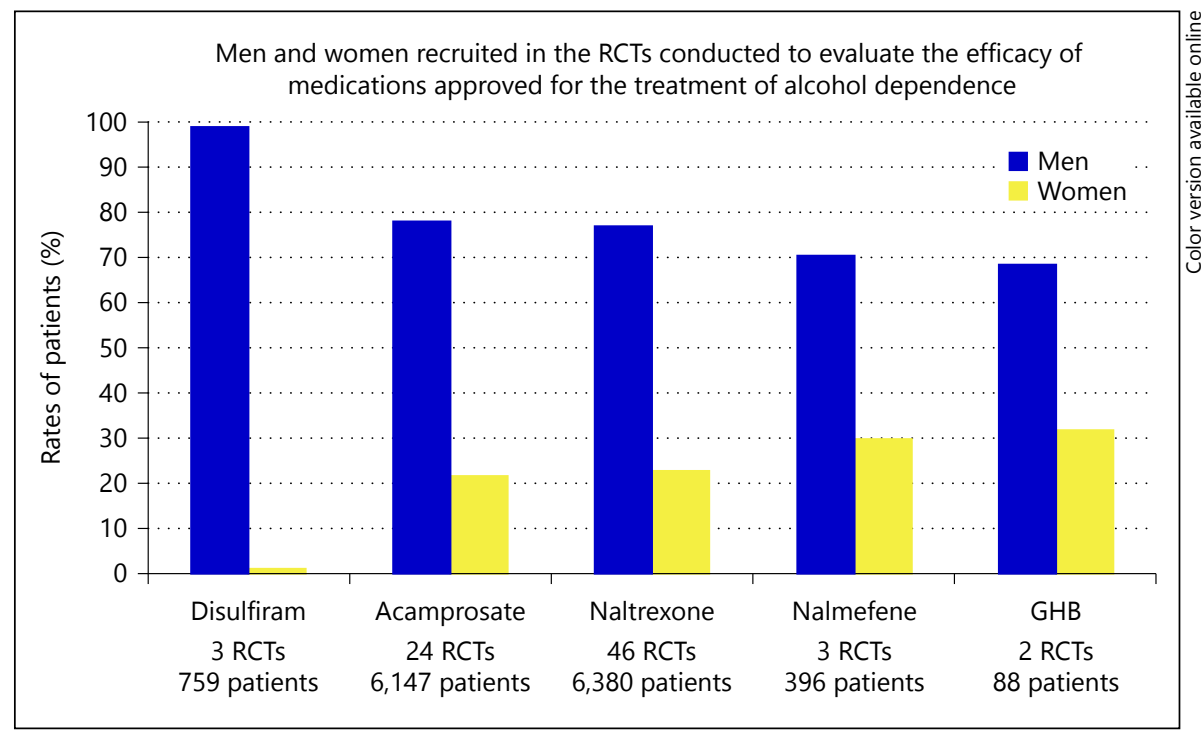

Table 3. Number of female patients recruited in the RCTs evaluated by the meta-analysis entitled 'The efficacy of disulfiram for the treatment of alcohol use disorder' by Jørgensen et al., 2011 [59]

\begin{tabular}{|c|c|c|c|c|}
\hline \multirow[t]{2}{*}{$n$} & \multirow[t]{2}{*}{ Study } & \multicolumn{2}{|c|}{ Women } & \multirow{2}{*}{$\begin{array}{l}\text { Total } \\
\text { patients, } \\
\mathrm{n}\end{array}$} \\
\hline & & $\mathrm{n}$ & $\%$ & \\
\hline 1 & De Sousa and De Sousa, 2004 & 0 & 0.0 & 100 \\
\hline 2 & De Sousa and De Sousa, 2005 & 0 & 0.0 & 100 \\
\hline 3 & De Sousa and De Sousa, 2008 & 0 & 0.0 & 100 \\
\hline 4 & De Sousa et al., 2008 & 0 & 0.0 & 58 \\
\hline 5 & Fuller and Roth, 1979 & $\mathbf{0}$ & 0.0 & 128 \\
\hline 6 & Fuller et al., 1986 & $\mathbf{0}$ & 0.0 & 605 \\
\hline 7 & Laaksonen et al., 2008 [60] & 71 & 29.2 & 243 \\
\hline 8 & Nava et al., 2006 & 12 & 15.0 & 80 \\
\hline 9 & Niederhofer and Staffen, 2003 & 9 & 34.6 & 26 \\
\hline 10 & Tonnesen et al., 1999 & 0 & 0.0 & 42 \\
\hline 11 & Ulrichsen et al., 2010 & n.a. & n.a. & 39 \\
\hline
\end{tabular}

n.a. = Data not available. In bold: studies in which disulfiram was compared to placebo. References are listed in online supplementary references.

The meta-analysis selected for naltrexone revealed that both oral and injectable long-acting formulations of this medication are superior to placebo primarily in reducing the risk of heavy drinking [55]. This meta-analysis evaluated the results of 50 RCTs: (a) 43 RCTs, in which patients received the oral formulation of naltrexone, (b) 4 RCTs in which patients received the injectable longacting formulation of naltrexone, and (c) 3 RCTs in which patients received nalmefene (see below). The rates of women recruited in the $50 \mathrm{RCTs}$ evaluated by this metaanalysis for naltrexone are shown by table 5 . Naltrexone was administered at fixed doses, regardless of body weight [55]. The daily dose of oral naltrexone ranged from 25 to $150 \mathrm{mg}$; most trials used $50 \mathrm{mg}$ per day. Injectable naltrexone was administered at 4 -week intervals at doses between 150 and $400 \mathrm{mg}$. According to the results obtained by the meta-analysis selected, the level A1 of efficacy for $\mathrm{AD}$ treatment was assigned to naltrexone, regardless of sex (table 2). Among the 47 RCTs for naltrexone (including 6,437 patients), globally, (a) 1 study did not indicate the number and gender of patients recruited, (b) 10 RCTs recruited only male patients $(n=721),(c) 35$ RCTs recruited both male and female patients $(1,376$ women in a sample of 5,613 subjects $(24.5 \%)$ ), and, interestingly, (d) 1 recruited only female patients $(n=103)$. Among the 6,437 patients for whom the sex was known, 1,479 were women (23.0\%). Forty-six RCTs compared naltrexone to placebo recruiting 1,468 women, in a sample of 6,380 patients $(23.0 \%)$. The rate of women recruited for evaluating the efficacy of naltrexone may allow comparison of results between female and male patients. However, this meta-analysis did not conduct a gender analysis [55]. Moreover, the majority of the studies evaluated by the meta-analysis did not report the results obtained by female patients in detail, while the few studies in which this information was reported found contrasting results. Namely, the RCT in which only female patients were recruited failed to demonstrate a significant effect of naltrexone [61]. In this RCT, naltrexone did not improve drinking outcomes, although naltrexone delayed the on- 
Table 4. Number of female patients recruited in the RCTs evaluated by the meta-analysis entitled 'acamprosate for alcohol dependence' by Rösner et al., 2010 [56]

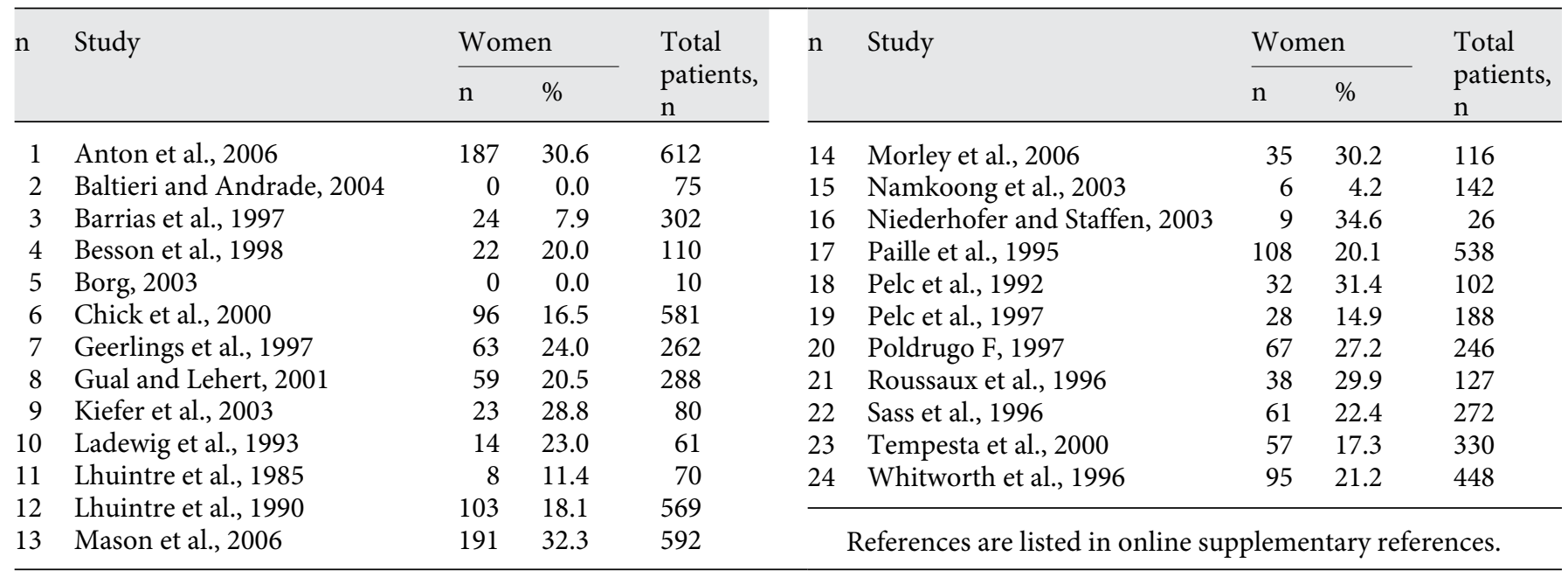

Table 5. Number of female patients recruited in the RCTs evaluated by the meta-analysis entitled 'opioid antagonists for alcohol dependence' by Rösner et al., 2010 [55]

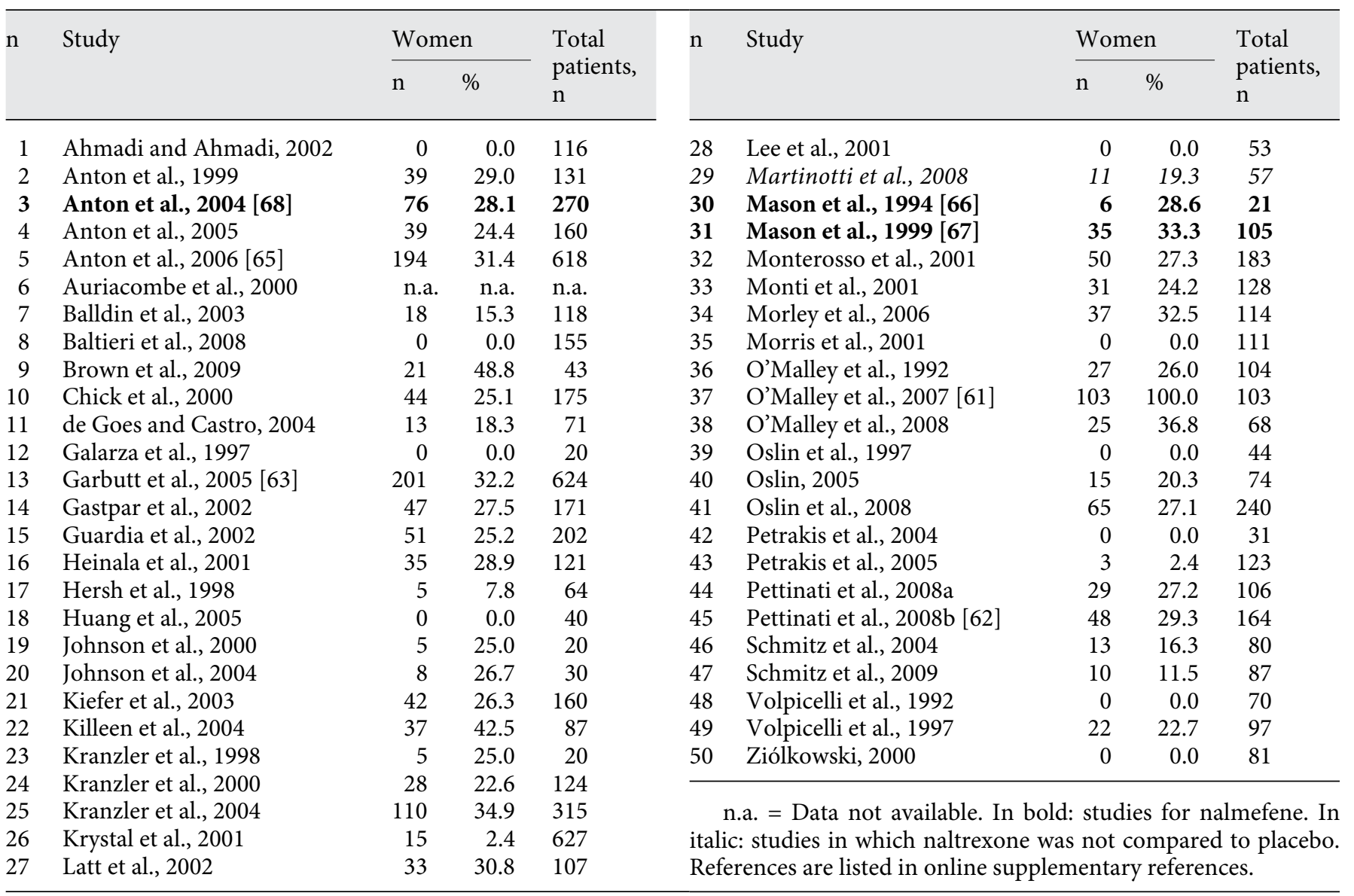


Table 6. Number of female patients recruited in the RCTs evaluated by the meta-analysis entitled 'Gamma-hydroxybutyrate (GHB) for treatment of alcohol withdrawal and prevention of relapses' by Leone et al., 2010 [58]

\begin{tabular}{|c|c|c|c|c|}
\hline \multirow[t]{2}{*}{$\mathrm{n}$} & \multirow[t]{2}{*}{ Study } & \multicolumn{2}{|c|}{ Women } & \multirow{2}{*}{$\begin{array}{l}\text { Total } \\
\text { patients } \\
\mathrm{n}\end{array}$} \\
\hline & & $\mathrm{n}$ & $\%$ & \\
\hline 1 & Addolorato et al., 1999 [72] & 9 & 15.0 & 60 \\
\hline 2 & Caputo et al., 2003 & 8 & 22.9 & 35 \\
\hline 3 & Caputo et al., 2007 & 12 & 21.8 & 55 \\
\hline 4 & Ceccanti et al., 1996 & 0 & 0.0 & 42 \\
\hline 5 & Di Bello et al., 1995 & 4 & 23.5 & 17 \\
\hline 6 & Elsing et al., 1996 & 3 & 14.3 & 21 \\
\hline 7 & Ferri et al., 1991 & n.a. & n.a. & 40 \\
\hline 8 & Gallimberti et al., 1989 & 7 & 30.4 & 23 \\
\hline 9 & Gallimberti et al., 1992 & 24 & 33.8 & 71 \\
\hline 10 & Nava et al., 2006 & 12 & 15.0 & 80 \\
\hline 11 & Nava et al., 2007 [74] & n.a. & n.a. & 42 \\
\hline 12 & Nimmerrichter et al., 2002 & 9 & 9.2 & 98 \\
\hline 13 & Stella et al., 2008 & 14 & 29.8 & 47 \\
\hline
\end{tabular}

n.a. = Data not available; In bold: studies in which GHB was compared to placebo. In italic: studies in which GHB was administered to reduce the severity of AWS. References are listed in online supplementary references.

set of subsequent drinking days among women who lapsed. This RCT also found a higher proportion of adverse effects among women treated with naltrexone (77\%) than among those who received placebo (52\%). Another RCT evaluated the efficacy of a higher dose of naltrexone compared to the typical one ( $150 \mathrm{mg}$ instead of $50 \mathrm{mg}$ per day) in 164 patients (48 women) with co-occurring cocaine and $\mathrm{AD}$ [62]. The results showed that men treated with naltrexone had reductions in cocaine and alcohol use and drug severity, whereas women did not benefit from this treatment. In fact, women who received naltrexone used more cocaine and had higher rates of drinking than women treated with placebo. Another RCT found that administration of injectable formulations of naltrexone yielded significant results in men (423 patients) but not in women (201 patients) [63]. In the latter RCT, women were more likely to report nausea than men. Conversely, a post-hoc analysis of another RCT evaluated by the meta-analysis ( 160 patients; 42 women) found that $\mathrm{AD}$ women treated with $50 \mathrm{mg}$ of naltrexone per day abstained from alcohol for a longer period than $\mathrm{AD}$ men did [64]. Finally, the COMBINE study found that naltrexone induced similar benefits in both men and women [65]. According to these results, it is not clear if women respond differently to naltrexone (tables 2 and 5 ).
The meta-analysis selected for nalmefene evaluated the results obtained by 3 RCTs and found no significant differences between patients who received this medication and those who received placebo [55]. Accordingly, the level $\mathrm{C}$ of efficacy was assigned to this medication, regardless of patient sex (table 2). Globally, the 3 RCTs recruited 117 women in a total sample of 396 subjects (29.5\%), and all RCTs compared nalmefene to placebo (table 5). The rate of women recruited for RCTs evaluating the efficacy of nalmefene was close to the real frequency of female patients with AD. However, the meta-analysis did not conduct a gender analysis, and the studies did not report the results obtained by female patients in detail [55, 66-68]. According to these results, it is not clear if women may respond differently to nalmefene. The doses of nalmefene ranged from 5 to $80 \mathrm{mg}$ [55].

The meta-analysis selected for GHB found that patients who received this medication achieved better results than patients who received placebo in treatment of both $\mathrm{AD}$ and AWS [58]. This meta-analysis evaluated the results obtained by 7 RCTs (including 345 patients) in which GHB was administered to reduce the risk of relapses, and 6 RCTs (including 286 patients) in which GHB was administered to reduce the severity of AWS. The rates of women recruited in these 13 RCTs are shown by table 6 . Globally, among the 7 RCTs for the prevention of relapses (a) 1 study did not indicate the gender of patients $(n=40)$, whereas $(b)$ the other 6 RCTs recruited both male and female patients for a total of 74 women in a sample of 305 patients $(24.3 \%)$. Among the 305 patients for whom the sex was known, 74 were women (24.3\%). Only 2 RCTs compared GHB to placebo ( 28 women in a sample 88 subjects $(31.8 \%)$ ). Among the 6 RCTs for AWS treatment (a) 2 studies did not indicate the gender of patients $(n=63),(b) 1$ RCT recruited only male patients $(\mathrm{n}=42)$, whereas (c) 3 RCTs recruited both male and female patients for a total of 25 women in a sample of 181 patients (13.8\%). Among the 223 patients for whom the sex was known, 25 were women (11.2\%). Only 1 RCT compared GHB to placebo ( 7 women in a sample of 23 patients $(30.4 \%))$. Considering the low number of patients recruited by RCTs, the level C of efficacy was assigned to GHB both for AD and AWS, regardless of sex (tables 2 and 7). The daily dose of GHB was always adjusted according to body weight $(50 \mathrm{mg} / \mathrm{kg}$ body weight, divided into 3 daily doses) [58]. It was not specified whether women received lower doses of GHB than men did.

Globally, the 4 meta-analyses selected reviewed 92 RCTs for AD treatment, in which almost 15,000 patients were recruited (table 2). Among these 92 RCTs, 19 (approximately $21 \%$ ) recruited only male patients, 3 studies 
Table 7. Information collected by selected meta-analyses on medications approved for the treatment of alcohol withdrawal syndrome

\begin{tabular}{llll}
\hline Medication & Benzodiazepines & Anticonvulsants & GHB \\
\hline Selected meta-analyses & Amato et al., & Minozzi et al., & Leone et al., \\
& $2010[69]$ & $2010[58]$ & $2010]$ \\
\hline
\end{tabular}

Characteristics of the RCTs evaluated by the selected meta-analyses

Total number of RCTs evaluated, $\mathrm{n}$

Total patients recruited in these RCTs, $\mathrm{n}$

RCTs in which only male patients were recruited, $n$

RCTs in which the sex of patients was not indicated, $n$

RCTs in which male and female patients were recruited, $n$

RCTs in which only female patients were recruited, $n$

Patients for whom sex was known, $\mathrm{n}$

Women, $\mathrm{n}$

Women, $\%$ of patients for whom sex was known

$\begin{array}{lll}65 & 58 & 6 \\ 4,612 & 4,218 & 286 \\ 21 & 11 & 1 \\ 9 & 8 & 2 \\ 35 & 39 & 3 \\ 0 & 0 & 0 \\ 4,025 & 3,619 & 223 \\ 414 & 460 & 25 \\ 10.3 & 12.7 & 11.2\end{array}$

Characteristics of the studies evaluated by the selected meta-analyses in which medications were compared to placebo

Total number of these RCTs, $n$

Total patients recruited in these RCTs, $n$

Women, $\mathrm{n}$

$12 \quad 17 \quad 1$

$1,301 \quad 23$

Women, $\%$ of patients for whom sex was known

Level of efficacy regardless of patient sex

Levels of efficacy in female patients

42

3.2

182

12.6

C

?

6

1

2

223

11.2

1

23
7

30.4

C

?

This table summarizes information collected by selected meta-analyses on the efficacy of medications approved for the treatment of alcohol withdrawal syndrome. Levels of efficacy range from A1 (the best) to C (the worst).

(3\%) did not specify the sex of patients, 1 RCT recruited only female patients, and the other 69 RCTs (75\%) recruited both female and male patients. The rate of women (among patients of whom sex was known) recruited by the RCTs in which the efficacy of medications was compared to that of placebo varied from $1.2 \%$ for disulfiram to $31.8 \%$ for GHB. None of the RCTs evaluated by selected meta-analyses reported the use of different doses of medications for female patients.

The second search for meta-analyses for AWS medications identified 21 articles: of these, 17 were excluded (see online suppl. references) and 4 were selected [58, 69-71]. A meta-analysis investigated the efficacy of GHB for the treatment of both AD and AWS [58]. Finally, 1 article was an overview of meta-analyses that compared the efficacy of different AWS medications [71]. Reasons for exclusion of meta-analyses are listed in online supplementary table S2. Information collected from the selected meta-analyses is summarised in table 7 .

The meta-analysis selected for benzodiazepines evaluated the results obtained by 65 RCTs, in which 4,612 patients were included, and demonstrated a significant effect of this class of drugs compared to placebo in treatment of AWS [69]. Accordingly, the level A1 of efficacy was as- signed to benzodiazepines, regardless of patient sex. The rates of women recruited in these 65 RCTs are shown by table 8. Globally, (a) 21 RCTs recruited only men ( $\mathrm{n}=$ 1,726), (b) 9 studies did not indicate the gender of patients ( $\mathrm{n}=587$ patients), and (c) 35 RCTs recruited both male and female patients (414 women in a sample of 2,249 subjects $(18.4 \%))$. Among the 4,025 patients for whom the sex was known, 414 were women (10.3\%). Twelve RCTs compared benzodiazepines to placebo (table 8). Among them, (a) 7 RCTs recruited only male patients ( $\mathrm{n}=1,035$ patients), (b) 1 study did not indicate the gender of subjects $(n=91$ patients), and (c) 4 RCTs recruited both male and female patients ( 42 women in a sample of 175 subjects $(24 \%)$ ). Among the 1,210 patients for whom the sex was known, 42 were women (3.5\%). In the evaluation of the efficacy of benzodiazepines compared to that of placebo, the meta-analysis included only 3 of these 12 RCTs: among them, 1 recruited only male patients ( $\mathrm{n}=537$ patients), and the other 2 recruited 13 women and 78 men. Globally, these 3 RCTs recruited 13 women in a sample of 628 patients (equal to $2.1 \%)$. The low number of women recruited in these RCTs did not allow the evaluation of possible gender differences in the response to these medications (fig. 2; tables 7 and 8). Among all 65 RCTs evaluated by the meta-analysis, only 3 
Table 8. Number of female patients recruited in the RCTs evaluated by the meta-analysis entitled 'benzodiazepines for alcohol withdrawal' by Amato et al., 2010 [69]

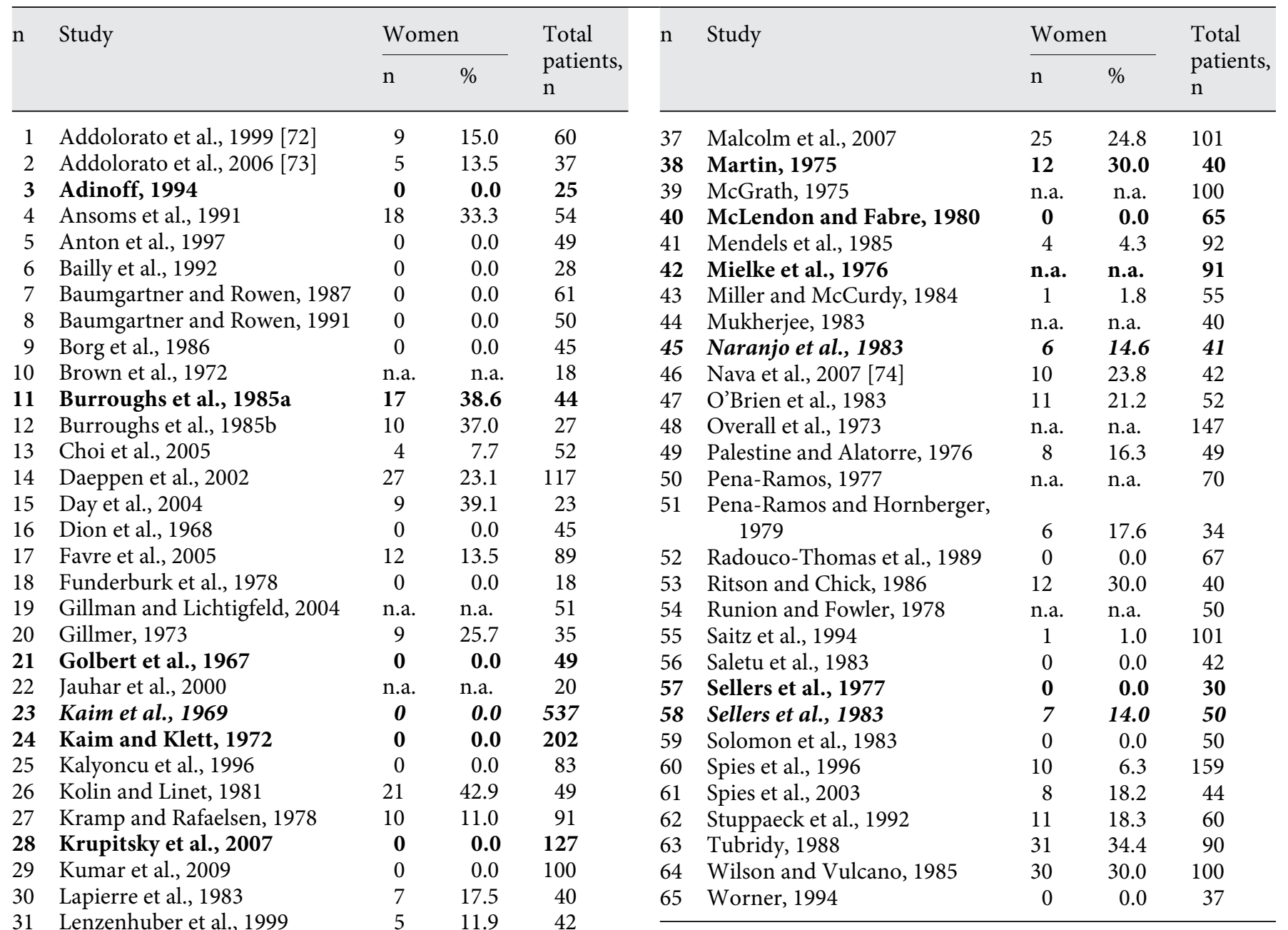

Lepola et al., 1984

33 Longo et al., 2002

34 Lucht et al., 2003

35 Malcolm et al., 1989

36 Malcolm et al., 2002

$11.7 \quad 60$

$50.0 \quad 16$

$7.1 \quad 127$

$0.0 \quad 66$

$25.0 \quad 136$

n.a. = Data not available. In bold: studies in which a BDZ was compared to placebo. In italic: studies analysed by the metaanalysis for the evaluation of the efficacy of benzodiazepines compared to placebo. References arelisted in online supplementary references.

studies adjusted benzodiazepine doses according to body weight [72-74]. In these studies, a daily oral dose of diazepam of $0.5-0.75 \mathrm{mg} / \mathrm{kg}$ body weight was administered for 6 days; then the dose was tapered off by $25 \%$ daily until day 10 in 139 patients, comprising 24 women. However, information on female patients was not provided.

The meta-analysis selected for anticonvulsants evaluated the results obtained by 58 RCTs, including 4,218 patients, and failed to demonstrate a significant effect of anticonvulsants compared to placebo in treatment of AWS [70]. Accordingly, the level $\mathrm{C}$ of efficacy was assigned to anticonvulsants, regardless of patient sex. The rates of women recruited in these 58 RCTs are shown by table 9. Globally, (a) 11 RCTs recruited only men $(\mathrm{n}=905)$, (b) 8 studies did not indicate the gender of patients $(n=599$ patients), and (c) 39 RCTs recruited both male and female patients ( 460 women in a sample of 2,714 subjects $(16.9 \%)$ ). Among the 3,619 patients for whom the sex was known, 460 were women (12.7\%). Seventeen RCTs compared anticonvulsants to placebo; among them, (a) 4 RCTs recruited only male patients ( $\mathrm{n}=489$ patients), (b) 1 study did not indicate the gender of subjects ( $\mathrm{n}=157$ patients), and (c) 
Fig. 2. Rates of male and female patients recruited in randomised, placebo-controlled trials conducted to evaluate the efficacy of AWS medications.

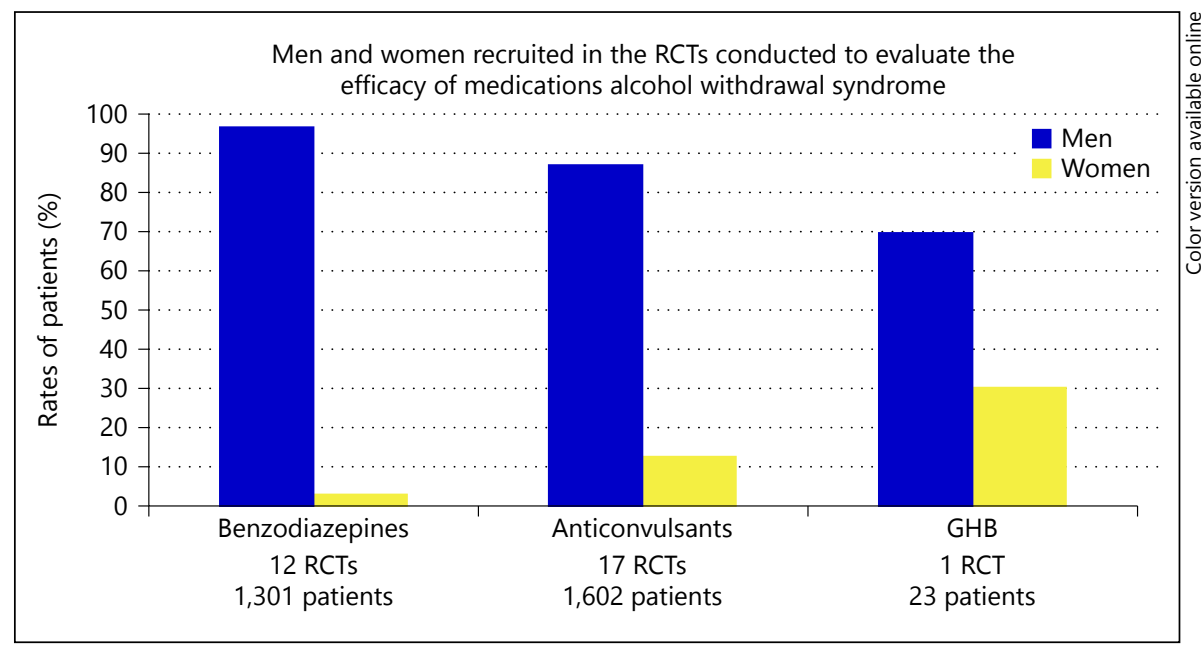

12 RCTs recruited both male and female patients (182 women in a sample of 956 subjects (19.0\%)). Among the 1,445 patients for whom the sex was known, 182 were women (12.6\%). In the evaluation of the efficacy of anticonvulsants compared to that of placebo, the meta-analysis included only 9 of these 17 RCTs. These 9 RCTs recruited 933 patients, including 106 women (13.7\%). The majority of the studies evaluated by the meta-analysis did not report the results obtained by female patients in details. Moreover, among these RCTs, some recruited a number of women too small to investigate possible gender differences (fig. 2; tables 7 and 9). According to these results, it is not clear if women may respond differently to anticonvulsants.

Globally, table 7 shows that, the 3 selected meta-analyses reviewed 129 studies for AWS medications, in which more than 9,000 subjects were recruited. Thirty-three out of 129 studies (approximately 26\%) recruited only male patients, 19 studies (15\%) did not specify the sex of patients, no study recruited only female patients, and the other 77 studies $(60 \%)$ recruited both female and male patients. The rate of women (among patients of whom sex was known) recruited by the studies in which the efficacy of medications was compared to that of placebo varied from $3.2 \%$ for benzodiazepines to $30.4 \%$ for GHB. None of the selected meta-analyses reported the use of different doses of medications for female patients.

\section{Discussion}

The results of this study showed that the rates of women recruited by studies evaluating the efficacy of disulfiram (1\%) for $\mathrm{AD}$ treatment and of benzodiazepines (3\%) and anticonvulsants (13\%) for AWS treatment were too low to establish possible sex differences in the response to these medications (fig. 1 and 2). The rate of women recruited for GHB was higher (32\%), but the total number of patients was too small ( 88 subjects) to reach any significant conclusion regarding its efficacy for the treatment of both AD and AWS. Finally, the rates of women recruited for acamprosate (22\%), naltrexone (23\%), and nalmefene (30\%) for $\mathrm{AD}$ treatment were sufficient to permit gender analysis, but the results of these comparisons are contrasting and not conclusive.

Acamprosate was the only medication that could achieve the best level of efficacy for $\mathrm{AD}$ treatment in female patients [56, 57]. However, in the COMBINE study, acamprosate failed to reduce alcohol consumption, regardless of patient sex [65]. Although these negative results were already evaluated in the selected meta-analysis [56], they deserve further explanation because of the large number of patients recruited [65]. Moreover, a gender analysis (not included in the meta-analysis we selected) of the results obtained by the COMBINE study specifically showed that acamprosate failed to reduce alcohol consumption in women as well as in men [75].

Naltrexone achieved the best level of efficacy regardless of the sex of patients, but it is not clear if women respond differently to this medication. Indeed, among the studies included in the selected meta-analysis, some found that naltrexone is not effective in female patients [61] or is more effective in men than in women $[62,63]$, whereas others found that naltrexone is more effective in women than in men [64]. The gender analysis on the results obtained by the COMBINE study found that naltrexone induced similar benefits in both men and wom- 
Table 9. Number of female patients recruited in the RCTs evaluated by the meta-analysis entitled 'anticonvulsants for alcohol withdrawal' by Minozzi et al., 2010 [70]

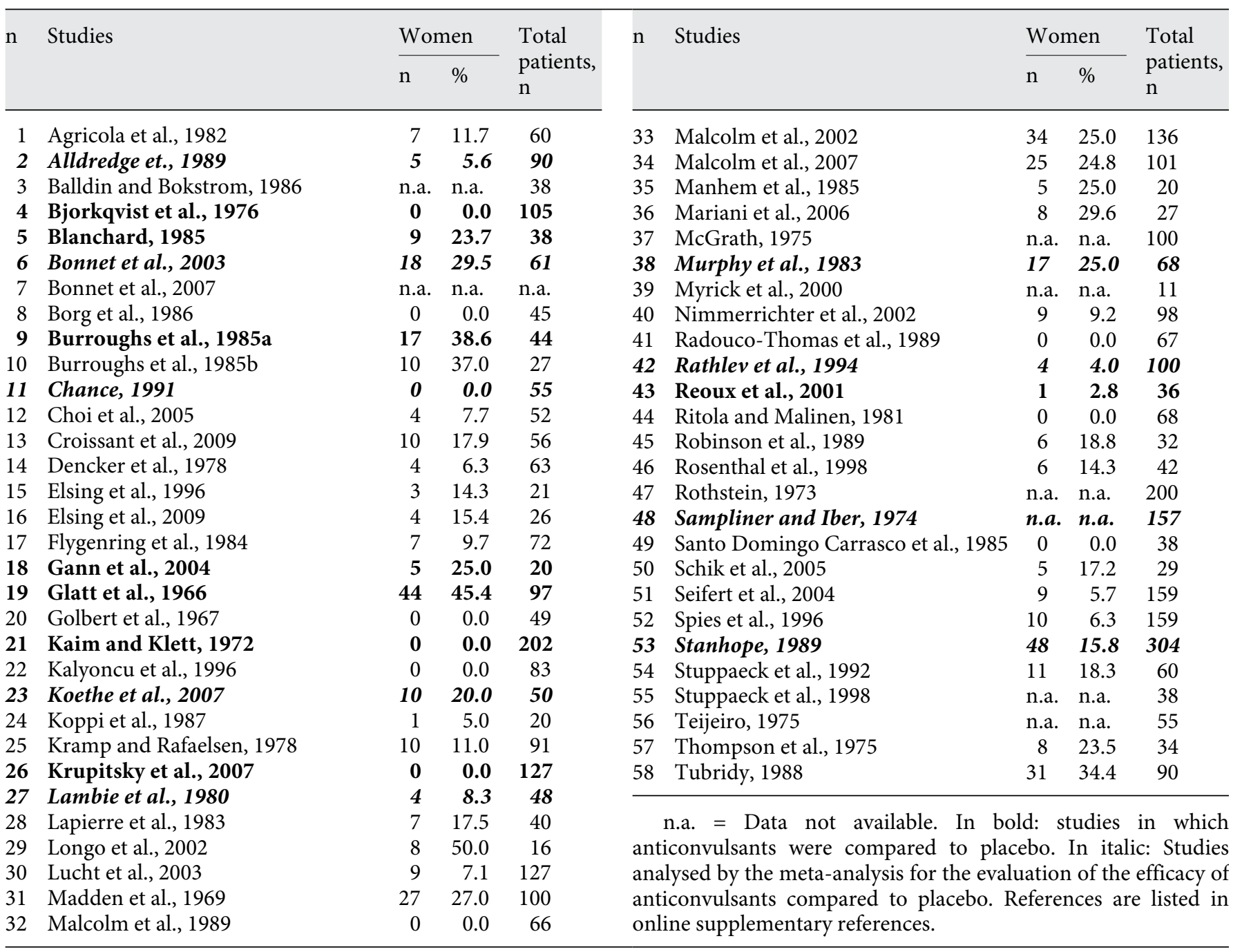

en, as well as another study not included in the selected meta-analysis $[75,76]$. It is important to note that in the COMBINE study, patients treated with naltrexone achieved better results than patients treated with placebo, while the results obtained did not differ between patients treated with acamprosate and patients treated with placebo [65]. Globally women reported more adverse effects than men with naltrexone treatment $[61,63]$.

The lack of information on the results obtained by female patients recruited by primary trials of the selected meta-analysis for nalmefene did not allow the possibility of conducting a gender-analysis [55]. Subsequent multicentre RCTs (not included in the meta-analysis we selected) - in which a total of $1,322 \mathrm{AD}$ patients (394 women) were re- cruited - found that nalmefene significantly reduced the number of heavy drinking days compared to placebo, with the same efficacy in both sexes $[77,78]$. This number of patients was three times higher than that in the RCTs evaluated by the meta-analysis we selected. Considering the results obtained by these recent studies, nalmefene may achieve the best level of efficacy both in female and in male AD patients. Nevertheless, the efficacy of nalmefene has recently been severely criticised [79]. It was calculated that nalmefene reduced alcohol consumption by approximately 1-2 units of alcohol per day in people who consumed an average of 13.5 units per day. The magnitude of this effect raises the question whether statistically significant benefits may be marginal in clinical practice [80]. 
Theoretically, disulfiram could acts differently in the two sexes. Indeed, one study (not included in the metaanalysis we selected) found that disulfiram was effective in men with cocaine and AD but not in women with the same disorders [81]. The use of disulfiram for the treatment of cocaine dependence is motivated by a mechanism of action other than ALDH inhibition. In details, the primary metabolite of disulfiram, S-methyl N,N-diethyldithiocarbamate sulphoxide, chelates copper and inhibits the function of enzymes that require copper as a cofactor [82]. One of these enzymes is dopamine $\beta$-hydroxylase $(\mathrm{D} \beta \mathrm{H})$, which converts dopamine to noradrenaline in the final step of noradrenaline synthesis in noradrenergic neurons [83]. Through $\mathrm{D} \beta \mathrm{H}$ inhibition, it has been found that disulfiram depletes noradrenaline and increases dopamine concentrations in rodents and humans, a mechanism proposed to explain the efficacy of disulfiram for cocaine dependence [83]. The sex difference in the response to disulfiram observed in patients with cocaine and $\mathrm{AD}$ may be due to the sex differences in $\mathrm{D} \beta \mathrm{H}$ activity, as oestrogens and oral contraceptives stimulate the activity of this enzyme [84, 85]. Accordingly, in women, the inhibition of $\mathrm{D} \beta \mathrm{H}$ activity due to disulfiram administration may be attenuated by the stimulating effect of $\mathrm{D} \beta \mathrm{H}$ activity induced by oestrogens and/or oral contraceptives. Another study, not included in the meta-analysis we selected, recently found an inverse relationship between the efficacy of disulfiram and $\mathrm{D} \beta \mathrm{H}$ activity in patients with cocaine dependence [86].

Sex differences have already been described for benzodiazepines in studies conducted for reasons other than AWS treatment, and not included in the meta-analysis we selected. These studies observed that women metabolise diazepam faster than men do $[87,88]$. This difference may be because diazepam is metabolised by the cytochrome enzymes CYP3A4 and CYP2C19, and CYP3A4 is more highly expressed in women than in men [21]. It is therefore possible that women and men may require different doses of benzodiazepines for AWS treatment, as already observed for zolpidem [26].

Women appear to be at higher risk than men to develop brain damage following chronic alcohol consumption [89, 90]. For instance, it has been found that AD women have smaller gray and white matter volumes and greater CSF volumes than healthy women, and that these differences are considerably larger than those found between alcoholic and healthy men, despite the fact that $\mathrm{AD}$ women have consumed large amounts of alcohol for fewer years than $\mathrm{AD}$ men [91]. The higher vulnerability to the neurotoxic effects of alcohol, and the subsequent increased severity of brain damage in $\mathrm{AD}$ women compared to $\mathrm{AD}$ men, might constitute a further cause of possible gender differences in response to $\mathrm{AD}$ medications. However, the complete lack of information on female patients does not allow the possibility of investigating the possible differences and potential explanations in response to pharmacotherapy.

In addition, the selected meta-analyses did not report the use of different doses of medications for male and female patients. The doses of some medications (e.g. acamprosate and $\mathrm{GHB}$ ) were adjusted according to body weight. As women usually have a lower body weight than men, it is possible that female patients received lower doses of these medications than male patients did. However, it was not specified.

Finally, the specific hormonal phases of women life (e.g. pregnancy) were not considered, even if many medications for $\mathrm{AD}$ and AWS belonged to FDA class $\mathrm{C}$ pregnancy risk [92]. Conversely, female patients should receive doses adjusted according to body weight, at least at the start of treatment and female AD patients of childbearing age should also be tested for pregnancy before starting pharmacological treatment.

In conclusion, women receive medications for treatment of AD and/or AWS for which efficacy has been demonstrated in studies in which men were more largely represented. The scarce enrolment of women strongly suggests that it is time to perform further studies to evaluate the efficacy and safety of AD and/or AWS medications in women considering different subgroups of the female population, such as adolescents, adults, and the elderly, to reveal gender differences in response to these medications and improve the quality of medical assistance for $\mathrm{AD}$ women. It is important to bear in mind that the majority of subjects with $\mathrm{AD}$ never receive treatment [35, 93]. Women are more likely than men to meet numerous barriers to accessing treatment, and pregnant women are less likely to receive $\mathrm{AD}$ therapy than non-pregnant women $[94,95]$. Improving knowledge of the efficacy and safety of medications for treating AD and/or AWS may contribute to the amelioration of the quality of medical assistance for $\mathrm{AD}$ women and increase the number of female patients who seek and receive medical treatment for this disorder.

\section{Disclosure Statement}

None declared. This study was partially supported by a grant from the Regione Sardegna 'Progetti di farmacovigilanza attiva, finanziabili attraverso i fondi $\mathrm{fv} 2008 / 09$ '. We are grateful to the Major of Osilo and all Municipal Hall for the laboratory space that they dedicated to the National Laboratory in Gender Medicine of INBB. 


\section{References}

1 Chick J, Nutt DJ: Substitution therapy for alcoholism: time for a reappraisal? J Psychopharmacol 2012;26:205-212.

2 Franck J, Jayaram-Lindström N: Pharmacotherapy for alcohol dependence: status of current treatments. Curr Opin Neurobiol 2013; 23:692-699.

3 Zindel LR, Kranzler HR: Pharmacotherapy of alcohol use disorders: seventy-five years of progress. J Stud Alcohol Drugs 2014;75:7988.

4 Suh JJ, Pettinati HM, Kampman KM, O'Brien CP: The status of disulfiram: a half of a century later. J Clin Psychopharmacol 2006;26: 290-302.

5 Skinner MD, Lahmek P, Pham H, Aubin HJ: Disulfiram efficacy in the treatment of alcohol dependence: a meta-analysis. PLoS One 2014; 9:e87366.

6 Gastfriend DR: Intramuscular extended-release naltrexone: current evidence. Ann N Y Acad Sci 2011;1216:144-166

7 Swift RM: Naltrexone and nalmefene: any meaningful difference? Biol Psychiatry 2013; 73:700-701.

8 Aubin HJ, Daeppen JB: Emerging pharmacotherapies for alcohol dependence: a systematic review focusing on reduction in consumption. Drug Alcohol Depend 2013;133: $15-29$.

9 Mark TL, Kassed CA, Vandivort-Warren R, Levit KR, Kranzler HR: Alcohol and opioid dependence medications: prescription trends, overall and by physician specialty. Drug Alcohol Depend 2009;99:345-349.

10 Witkiewitz K, Saville K, Hamreus K: Acamprosate for treatment of alcohol dependence: mechanisms, efficacy, and clinical utility. Ther Clin Risk Manag 2012;8:45-53.

11 Littleton JM: Acamprosate in alcohol dependence: implications of a unique mechanism of action. J Addict Med 2007;1:115-125.

12 Kiefer F, Mann K: Acamprosate: how, where, and for whom does it work? Mechanism of action, treatment targets, and individualized therapy. Curr Pharm Des 2010;16:2098-2102.

13 Agabio R, Carai MAM, Gessa GL, Colombo G: Gamma-hydroxybutyric acid (GHB); in Koob GF, Le Moal M, Thompson RF (eds): Encyclopedia of Behavioral Neuroscience, Elsevier Science, 2010.

14 Carter LP, Pardi D, Gorsline J, Griffiths RR: Illicit gamma-hydroxybutyrate (GHB) and pharmaceutical sodium oxybate (Xyrem): differences in characteristics and misuse. Drug Alcohol Depend 2009;104:1-10.

15 van Amsterdam JG, Brunt TM, McMaster MT, Niesink RJ: Possible long-term effects of $\gamma$-hydroxybutyric acid (GHB) due to neurotoxicity and overdose. Neurosci Biobehav Rev 2012;36:1217-1227.

16 Mayo-Smith MF: Pharmacological management of alcohol withdrawal. A meta-analysis and evidence-based practice guideline. JAMA 1997;278:144-151.
17 Hall W, Zador D: The alcohol withdrawal syndrome. Lancet 1997;349:1897-1900.

18 Kosten TR, O'Connor PG: Management of drug and alcohol withdrawal. N Engl J Med 2003;348:1786-1795.

19 Johnson BA: Medication treatment of different types of alcoholism. Am J Psychiatry 2010 167:630-639.

20 Leggio L, Kenna GA, Fenton M, Bonenfant E, Swift RM: Typologies of alcohol dependence. From Jellinek to genetics and beyond. Neuropsychol Rev 2009;19:115-129.

21 Franconi F, Brunelleschi S, Steardo L, Cuomo $\mathrm{V}$ : Gender differences in drug responses. Pharmacol Res 2007;55:81-95.

22 Franconi F, Campesi I: Pharmacogenomics, pharmacokinetics and pharmacodynamics: interaction with biological differences between men and women. Br J Pharmacol 2014; 171:580-594.

23 Gandhi M, Aweeka F, Greenblatt RM, Blaschke TF: Sex differences in pharmacokinetics and pharmacodynamics. Annu Rev Pharmacol Toxicol 2004;44:499-523.

24 Marazziti D, Baroni S, Picchetti M, Piccinni A, Carlini M, Vatteroni E, Falaschi V, Lombardi A, Dell'Osso L: Pharmacokinetics and pharmacodynamics of psychotropic drugs: effect of sex. CNS Spectr 2013;18: $118-127$.

25 Soldin OP, Mattison DR: Sex differences in pharmacokinetics and pharmacodynamics. Clin Pharmacokinet 2009;48:143-157.

26 Kuehn BM: FDA warning: driving may be impaired the morning following sleeping pill use. JAMA 2013;309:645-646.

27 Verster JC, Roth T: Gender differences in highway driving performance after administration of sleep medication: a review of the literature. Traffic Inj Prev 2012;13:286-292.

28 Carroll ME, Anker JJ: Sex differences and ovarian hormones in animal models of drug dependence. Horm Behav 2010;58:44-56.

29 Ceylan-Isik AF, McBride SM, Ren J: Sex difference in alcoholism: who is at a greater risk for development of alcoholic complication? Life Sci 2010;87:133-138.

30 Hernandez-Avila CA, Rounsaville BJ, Kranzler HR: Opioid-, cannabis- and alcohol-dependent women show more rapid progression to substance abuse treatment. Drug Alcohol Depend 2004;74:265-272.

31 Sharrett-Field L, Butler TR, Reynolds AR, Berry JN, Prendergast MA: Sex differences in neuroadaptation to alcohol and withdrawal neurotoxicity. Pflugers Arch 2013;465:643654.

32 Walitzer KS, Dearing RL: Gender differences in alcohol and substance use relapse. Clin Psychol Rev 2006;26:128-148.

33 Wilsnack RW, Wilsnack SC, Kristjanson AF, Vogeltanz-Holm ND, Gmel G: Gender and alcohol consumption: patterns from the multinational GENACIS project. Addiction 2009; 104:1487-1500.
34 Witt ED: Puberty, hormones, and sex differences in alcohol abuse and dependence. Neurotoxicol Teratol 2007;29:81-95.

35 Hasin DS, Stinson FS, Ogburn E, Grant BF Prevalence, correlates, disability, and comorbidity of DSM-IV alcohol abuse and dependence in the United States: results from the national epidemiologic survey on alcohol and related conditions. Arch Gen Psychiatry 2007; 64:830-842.

36 Riley EP, Infante MA, Warren KR: Fetal alcohol spectrum disorders: an overview. Neuropsychol Rev 2011;21:73-80.

37 Sokol RJ, Delaney-Black V, Nordstrom B: Fetal alcohol spectrum disorder. JAMA 2003; 290:2996-2999.

38 Baraona E, Abittan CS, Dohmen K, Moretti M, Pozzato G, Chayes ZW, Schaefer C, Lieber CS: Gender differences in pharmacokinetics of alcohol. Alcohol Clin Exp Res 2001;25: 502-507.

39 Frezza M, di Padova C, Pozzato G, Terpin M BAraona E, Lieber CS: High blood alcohol levels in women. The role of decreased gastric alcohol dehydrogenase activity and first-pass metabolism. N Engl J Med 1990;322:95-99.

40 Parlesak A, Billinger MH, Bode C, Bode JC: Gastric alcohol dehydrogenase activity in man: influence of gender, age, alcohol consumption and smoking in a Caucasian population. Alcohol Alcohol 2002;37:388-393.

41 Vivian JA, Green HL, Young JE, Majerksy LS, Thomas BW, Shively CA, Tobin JR, Nader MA, Grant KA: Induction and maintenance of ethanol self-administration in cynomolgus monkeys (Macaca fascicularis): long-term characterization of sex and individual differences. Alcohol Clin Exp Res 2001;25:10871097.

42 Finn DA, Beckley EH, Kaufman KR, Ford MM: Manipulation of GABAergic steroids: sex differences in the effects on alcohol drinking- and withdrawal-related behaviors. Horm Behav 2010;57:12-22.

43 Loi B, Colombo G, Maccioni P, Carai MA, Franconi F, Gessa GL: High alcohol intake in female Sardinian alcohol-preferring rats. Alcohol 2014;48:345-351.

44 Fillmore MT, Weafer J: Alcohol impairment of behavior in men and women. Addiction 2004;99:1237-1246.

45 Webb B, Burnett PW, Walker DW: Sex differences in ethanol-induced hypnosis and hypothermia in young long-evans rats. Alcohol Clin Exp Res 2002;26:695-704.

46 Deshmukh A, Rosenbloom MJ, Sassoon S, O'Reilly A, Pfefferbaum A, Sullivan EV: Alcoholic men endorse more DSM-IV withdrawal symptoms than alcoholic women matched in drinking history. J Stud Alcohol 2003;64:375379

47 Leishman E, Kokesh KJ, Bradshaw HB: Lipids and addiction: how sex steroids, prostaglandins, and cannabinoids interact with drugs of abuse. Ann N Y Acad Sci 2013;1282:25-38. 
48 Fattore L, Melis M, Fadda P, Fratta W: Sex differences in addictive disorders. Front Neuroendocrinol 2014;35:272-284.

49 Wiren KM, Hashimoto JG, Alele PE, Devaud LL, Price KL, Middaugh LD, Grant KA, Finn DA: Impact of sex: determination of alcohol neuroadaptation and reinforcement. Alcohol Clin Exp Res 2006;30:233-242.

50 Lenz B, Müller CP, Stoessel C, Sperling W, Biermann T, Hillemacher T, Bleich S, Kornhuber J: Sex hormone activity in alcohol addiction: integrating organizational and activational effects. Prog Neurobiol 2012;96:136163.

51 Boileau I, Assaad JM, Pihl RO, Benkelfat C, Leyton M, Diksic M, Tremblay RE, Dagher A: Alcohol promotes dopamine release in the human nucleus accumbens. Synapse 2003;49: 226-231.

52 Balshem H, Helfand M, Schünemann HJ, Oxman AD, Kunz R, Brozek J, Vist GE, Falck-Ytter Y, Meerpohl J, Norris S, Guyatt GH: GRADE guidelines: 3 . Rating the quality of evidence. J Clin Epidemiol 2011;64:401406.

53 Guyatt GH, Oxman AD, Kunz R, Vist GE, Falck-Ytter Y, Schünemann HJ; GRADE Working Group: What is 'quality of evidence' and why is it important to clinicians? BMJ 2008;336:995-998.

54 Langendam MW, Akl EA, Dahm P, Glasziou $P$, Guyatt $G$, Schünemann $\mathrm{HJ}$ : Assessing and presenting summaries of evidence in Cochrane Reviews. Syst Rev 2013;2:81.

55 Rösner S, Hackl-Herrwerth A, Leucht S, Vecchi S, Srisurapanont M, Soyka M: Opioid antagonists for alcohol dependence. Cochrane Database Syst Rev 2010;12:CD001867.

56 Rösner S, Hackl-Herrwerth A, Leucht S, Lehert P, Vecchi S, Soyka M: Acamprosate for alcohol dependence. Cochrane Database Syst Rev 2010;9:CD004332.

57 Mason BJ, Lehert P: Acamprosate for alcohol dependence: a sex-specific meta-analysis based on individual patient data. Alcohol Clin Exp Res 2012;36:497-508.

58 Leone MA, Vigna-Taglianti F, Avanzi G, Brambilla R, Faggiano F: Gamma-hydroxybutyrate (GHB) for treatment of alcohol withdrawal and prevention of relapses. Cochrane Database Syst Rev 2010;2:CD006266.

59 Jørgensen $\mathrm{CH}$, Pedersen B, Tønnesen H: The efficacy of disulfiram for the treatment of alcohol use disorder. Alcohol Clin Exp Res 2011;35:1749-1758.

60 Laaksonen E, Koski-Jännes A, Salaspuro M, Ahtinen $\mathrm{H}$, Alho $\mathrm{H}$ : A randomized, multicentre, open-label, comparative trial of disulfiram, naltrexone and acamprosate in the treatment of alcohol dependence. Alcohol Alcohol 2008;43:53-61.

61 O'Malley SS, Sinha R, Grilo CM, Capone C, Farren CK, McKee SA, Rounsaville BJ, Wu R: Naltrexone and cognitive behavioral coping skills therapy for the treatment of alcohol drinking and eating disorder features in alcohol-dependent women: a randomized con- trolled trial. Alcohol Clin Exp Res 2007;31: 625-634.

62 Pettinati HM, Kampman KM, Lynch KG, Suh JJ, Dackis CA, Oslin DW, O'Brien CP: Gender differences with high-dose naltrexone in patients with co-occurring cocaine and alcohol dependence. J Subst Abuse Treat 2008;34: 378-390.

63 Garbutt JC, Kranzler HR, O’Malley SS, Gastfriend DR, Pettinati HM, Silverman BL, Loewy JW, Ehrich EW; Vivitrex Study Group: Efficacy and tolerability of long-acting injectable naltrexone for alcohol dependence: a randomized controlled trial. JAMA 2005;293: $1617-1625$.

64 Kiefer F, Jahn H, Wiedemann K: A neuroendocrinological hypothesis on gender effects of naltrexone in relapse prevention treatment. Pharmacopsychiatry 2005;38:184-186.

65 Anton RF, O'Malley SS, Ciraulo DA, Cisler RA, Couper D, Donovan DM, Gastfriend DR, Hosking JD, Johnson BA, LoCastro JS, Longabaugh R, Mason BJ, Mattson ME, Miller WR, Pettinati HM, Randall CL, Swift R, Weiss RD, Williams LD, Zweben A; COMBINE Study Research Group: Combined pharmacotherapies and behavioral interventions for alcohol dependence: the COMBINE study: a randomized controlled trial. JAMA 2006;295:20032017.

66 Mason BJ, Ritvo EC, Morgan RO, Salvato FR, Goldberg G, Welch B, Mantero-Atienza E: A double-blind, placebo-controlled pilot study to evaluate the efficacy and safety of oral nalmefene $\mathrm{HCl}$ for alcohol dependence. Alcohol Clin Exp Res 1994;18:1162-1167.

67 Mason BJ, Salvato FR, Williams LD, Ritvo EC, Cutler RB. A double-blind, placebo-controlled study of oral nalmefene for alcohol dependence. Arch Gen Psychiatry 1999;56:719724.

68 Anton RF, Pettinati H, Zweben A, Kranzler HR, Johnson B, Bohn MJ, McCaul ME, Anthenelli R, Salloum I, Galloway G, Garbutt J, Swift R, Gastfriend D, Kallio A, Karhuvaara S: A multi-site dose ranging study of nalmefene in the treatment of alcohol dependence. J Clin Psychopharmacol 2004;24:421-428.

69 Amato L, Minozzi S, Vecchi S, Davoli M: Benzodiazepines for alcohol withdrawal. Cochrane Database Syst Rev 2010;3: CD005063.

70 Minozzi S, Amato L, Vecchi S, Davoli M: Anticonvulsants for alcohol withdrawal. Cochrane Database Syst Rev 2010;3:CD005064.

71 Amato L, Minozzi S, Davoli M: Efficacy and safety of pharmacological interventions for the treatment of the alcohol withdrawal syndrome. Cochrane Database Syst Rev 2011; 6:CD008537

72 Addolorato G, Balducci G, Capristo E, Attilia ML, Taggi F, Gasbarrini G, Ceccanti M: Gamma-hydroxybutyric acid (GHB) in the treatment of alcohol withdrawal syndrome: a randomized comparative study versus benzodiazepine. Alcohol Clin Exp Res 1999;23: 1596-1604.
73 Addolorato G, Leggio L, Abenavoli L, Agabio R, Caputo F, Capristo E, Colombo G, Gessa GL, Gasbarrini G: Baclofen in the treatment of alcohol withdrawal syndrome: a comparative study vs diazepam. Am J Med 2006;119: 276.e13-e18.

74 Nava F, Premi S, Manzato E, Campagnola W, Lucchini A, Gessa GL: Gamma-hydroxybutyrate reduces both withdrawal syndrome and hypercortisolism in severe abstinent alcoholics: an open study vs. diazepam. Am J Drug Alcohol Abuse 2007;33:379-392.

75 Greenfield SF, Pettinati HM, O'Malley S, Randall PK, Randall CL: Gender differences in alcohol treatment: an analysis of outcome from the COMBINE study. Alcohol Clin Exp Res 2010;34:1803-1812.

76 Baros AM, Latham PK, Anton RF: Naltrexone and cognitive behavioral therapy for the treatment of alcohol dependence: do sex differences exist? Alcohol Clin Exp Res 2008;32:771776.

77 Gual A, He Y, Torup L, van den Brink W, Mann K; ESENSE 2 Study Group: A randomised, double-blind, placebo-controlled, efficacy study of nalmefene, as-needed use, in patients with alcohol dependence. Eur Neuropsychopharmacol 2013;23: 1432-1442.

78 Mann K, Bladström A, Torup L, Gual A, van den Brink W: Extending the treatment options in alcohol dependence: a randomized controlled study of as-needed nalmefene. Biol Psychiatry 2013;73:706-713.

79 Spence D: Bad medicine: nalmefene in alcohol misuse. BMJ 2014;348:g1531.

80 Greenhalgh T, Howick J, Maskrey N; Evidence Based Medicine Renaissance Group: Evidence based medicine: a movement in crisis? BMJ 2014;348:g3725.

81 Nich C, McCance-Katz EF, Petrakis IL, Cubells JF, Rounsaville BJ, Carroll KM: Sex differences in cocaine-dependent individuals' response to disulfiram treatment. Addict Behav 2004;29:1123-1128.

82 Hald J, Jacobsen E: A drug sensitizing the organism to ethyl alcohol. Lancet 1948;2:10011004.

83 Barth KS, Malcolm RJ: Disulfiram: an old therapeutic with new applications. CNS Neurol Disord Drug Targets 2010;9:5-12.

84 Rockson SG, Stone RA, Gunnells JC, Schanberg SM, Kirshner N, Robinson RR: Plasma dopamine-beta-hydroxylase activity in oral contraceptive hypertension. Circulation 1975; 51:916-923.

85 Serova L, Rivkin M, Nakashima A, Sabban EL: Estradiol stimulates gene expression of norepinephrine biosynthetic enzymes in rat locus coeruleus. Neuroendocrinology 2002; 75 : 193-200.

86 Kosten TR, Wu G, Huang W, Harding MJ, Hamon SC, Lappalainen J, Nielsen DA: Pharmacogenetic randomized trial for cocaine abuse: disulfiram and dopamine $\beta$-Hydroxylase. Biol Psychiatry 2013;73:219224. 
87 Ochs HR, Greenblatt DJ, Divoll M, Abernethy DR, Feyerabend H, Dengler HJ: Diazepam kinetics in relation to age and sex. Pharmacology 1981;23:24-30.

88 Chetty M, Mattison D, Rostami-Hodjegan A: Sex differences in the clearance of CYP3A4 substrates: exploring possible reasons for the substrate dependency and lack of consensus. Curr Drug Metab 2012;13:778-786.

89 Greenfield SF, Back SE, Lawson K, Brady KT: Substance abuse in women. Psychiatr Clin North Am 2010;33:339-355.
90 Nolen-Hoeksema S, Hilt L: Possible contributors to the gender differences in alcohol use and problems. J Gen Psychol 2006;133:357-374.

91 Hommer D, Momenan R, Kaiser E, Rawlings R: Evidence for a gender-related effect of alcoholism on brain volumes. Am J Psychiatry 2001;158:198-204.

92 Kweder SL: Drugs and biologics in pregnancy and breastfeeding: FDA in the 21st century. Birth Defects Res A Clin Mol Teratol 2008;82: 605-609.

93 Cohen E, Feinn R, Arias A, Kranzler HR: Alcohol treatment utilization: findings from the national epidemiologic survey on alcohol and related conditions. Drug Alcohol Depend 2007;86:214-221.
94 Greenfield SF, Brooks AJ, Gordon SM, Green CA, Kropp F, McHugh RK, Lincoln M, Hien D, Miele GM: Substance abuse treatment entry, retention, and outcome in women: a review of the literature. Drug Alcohol Depend 2007;86:1-21.

95 Terplan M, McNamara EJ, Chisolm MS: Pregnant and non-pregnant women with substance use disorders: the gap between treatment need and receipt. J Addict Dis 2012; 31:342-349. 